\title{
La represión de la protesta estudiantil durante el franquismo (1936-1976)
}

\author{
The Repression of Student's Protests during \\ Francoism (1936-1976)
}

\author{
Eduardo González Calleja* \\ Universidad Carlos III de Madrid \\ ORCID ID: 0000-0003-1184-4383
}

$\begin{array}{ll}\text { Recibido: } & 12 / 02 / 2020 \\ \text { Aceptado: } & 30 / 04 / 2020\end{array}$

D0I: https://doi.org/10.20318/cian.2020.5427

\begin{abstract}
Resumen: El artículo trata de aplicar el modelo elaborado por Charles Tilly para explicar las diferentes estrategias del Estado frente a las acciones de protesta a un caso particular: el trato dispensado por la dictadura franquista al movimiento estudiantil a lo largo de su trayectoria. Para ello se acotan las diversas etapas históricas del régimen, en las que se fueron combinando en diverso grado las prácticas de represión (centradas en el incremento de los costes de la movilización), de facilitamiento (oferta parcial y ocasional de incentivos positivos) y de tolerancia hacia las acciones colectivas de protesta de este particular grupo socioprofesional.

Palabras clave: España, franquismo, movimiento estudiantil, represión, universidad.
\end{abstract}

Abstract: The article tries to apply the model developed by Charles Tilly to explain the different strategies of the State against protest actions to a particular case: the treatment granted by the Franco's dictatorship to the student movement throughout its trajectory. To do this, the various historical stages of the regime are delimited, in which they were combined repression practices (increase of mobilization costs), facilitation (partial and occasional offer of positive incentives) and tolerance towards collective protest actions of this particular socio-professional group.

Keywords: francoism, repression, Spain, student movement, university.

\footnotetext{
*edgcalle@hum.uc3m.es
} 
Sobre el concepto de represión y sus diferentes declinaciones

Desde la perspectiva clásica de la ciencia política, la represión es una de las posibles acciones reguladoras que los gobiernos adoptan contra los individuos o los grupos que desafían las relaciones existentes de poder ${ }^{1}$. Ha sido definida como el empleo o la amenaza de coerción en grado variable, aplicada por los gobiernos contra los opositores reales o potenciales con vistas a debilitar su resistencia frente a la voluntad de las autoridades ${ }^{2}$. La represión engloba un amplio abanico de actuaciones, que pueden ir desde la eliminación física del disidente hasta el dirigismo de conductas públicas y privadas, en cuyo caso aparece como más cercana al concepto de control social. Éste engloba los medios de intervención, positivos o negativos, que utiliza un sistema político y social para conformar a sus miembros a las normas que le caracterizan, impedir o desanimar los comportamientos desviados y reconstruir las condiciones de consenso en caso de un cambio en el sistema normativo ${ }^{3}$.

Las teorías sociológicas adscritas al paradigma de la acción colectiva son las que han reflexionado más profundamente sobre el concepto de represión, entendida como una táctica que incide de forma destacada en la estructura de oportunidades, la cual puede ser definida como el contexto externo (en esencia, la actitud del Estado) que facilita o dificulta la captación de los recursos imprescindibles (dinero, armas, organización, alianzas, libertad de actuación, etc.) para el desarrollo y los fines de un movimiento de protesta. Desde esta perspectiva, la represión es un incentivo selectivo de carácter negativo a la participación en un movimiento; es un proceso externo que hace aumentar los costes de la acción colectiva en sus dos principales condiciones: la organización de la protesta y la movilización de la opinión pública ${ }^{4}$. Para que la represión actúe con eficacia, un gobierno o un contramovimiento pueden incrementar los costes de la movilización de sus enemigos desarticulando su organización, dificultando o impidiendo sus comunicaciones y bloqueando los recursos a su disposición: posiciones institucionales (en la burocracia, en los órganos legislativos, en la jerarquía judicial, etc.), influencia (experiencia,

\footnotetext{
${ }^{1}$ Christian Davenport, "The Weight of the Past: Exploring Lagged Determinants of Political Repression", Political Research Quarterly 49, no. 2 (junio 1996): 377 nota 1.

${ }^{2}$ Michel Stohl y George A. Lopez, "Introduction" a Michael Stohl y George A. Lopez, The State as Terrorist (Westport: Greenwood, 1984), 7.

${ }^{3}$ Franco Garelli, "Controllo sociale", en Norberto Bobbio, Nicola Matteucci y Gianfranco Pasquino (eds.), Dizionario di Politica (Turín: TEA/UTET, 1990), 232.

${ }^{4}$ Charles Tilly, From Mobilization to Revolution (Nueva York: Random House/McGraw-Hill, 1978), 100-102.
} 
información, dominio de los medios de comunicación, patronazgo, capacidad de convocatoria social...) y medios coercitivos (policiales, militares, paramilitares, insurreccionales...). También puede actuar directamente sobre los costes de la acción incrementando los castigos (penas, multas, sanciones a administrativas...), haciendo inaccesibles los objetivos de la acción (defensa armada de los lugares estratégicos) o induciendo a un derroche de los recursos movilizados por los grupos de protesta a través de la intervención de agentes provocadores. Para Donatella Della Porta, el control de la protesta es uno de los factores de la estructura de oportunidades políticas que influye más directamente sobre los movimientos sociales, hasta el punto de que las estrategias de la protesta y del control interactúan recíprocamente, provocando innovación y adaptación. Las respuestas estatales a la protesta, de carácter político, policial, judicial, está mediada por variables culturales, y a la vez tiene importantes efectos sobre la definición y la concepción de las oportunidades disponibles para los activistas ${ }^{5}$.

En todo caso, la voluntad coactiva de un gobierno es siempre selectiva, y consiste en una combinación de represión sobre unos grupos y de facilitamiento (oferta de incentivos positivos) para otros, mientras que la tolerancia es el espacio no determinado, esa "tierra de nadie" que suele existir entre las intervenciones coactivas y de fomento de la acción colectiva.

\begin{tabular}{|l|c|c|}
\hline & Anticipatoria & De respuesta \\
\hline Represión & Acciones preventivas y amenazas & Represalias \\
\hline Facilitamiento & Movilización controlada & Recompensas \\
\hline
\end{tabular}

Estrategias del Estado para tratar las acciones de protesta (Charles Tilly, Regimes and Repertories (ChicagoLondres: The University of Chicago Press, 2006), 74.

La naturaleza del régimen y la correlación de fuerzas políticas influyen de forma decisiva en las actitudes coactivas de los Estados ante los movimientos de protesta. Las diferentes modalidades de ejercicio del poder manifiestan actitudes muy distintas respecto de la movilización y la participación colectivas: Un régimen de tendencia totalitaria como pudo ser el franquismo en sus primeros años, mantiene alto el nivel de represión general, pero facilita e incluso hace obligatorias un amplio elenco de acciones controladas por el Estado, y se muestra extremadamente intolerante con todo tipo de actitud independiente, generando niveles medios de violencia en las interacciones con-

${ }^{5}$ Donatella Della Porta, Social Movements, Political Violence, and the State. A Comparative Analysis of Italy and Germany (Cambridge: Cambridge University Press, 1995), 57. 
flictivas, ya que la contestación es relativamente débil. Un régimen autoritario poco movilizado, como fue el pleno franquismo, facilita a regañadientes la acción colectiva de sus seguidores, mientras que muestra una tolerancia muy relativa respecto de las protestas no institucionales, pero tampoco subversivas. La confrontación política se da en el contexto de las escasas movilizaciones ilegales, que generan una respuesta represiva desproporcionada, con un nivel relativamente alto de violencia ocasional. Un régimen débil, como en este sentido fue el representado por el Gobierno presidido por Carlos Arias Navarro, previo al tránsito a la democracia, se ve obligado a incrementar los umbrales de tolerancia, imponiendo un número reducido de actuaciones prescritas, pero facilitando menos la acción colectiva de protesta. Coarta la actividad de la mayor parte de los grupos disidentes mediante la represión anticipatoria contra los grupos menos poderosos, mientras que se muestra impotente en incluso condescendiente frente a las presiones de los poderosos. El resultado es el despliegue de niveles medios de violencia en las interacciones de confrontación. Por último, un régimen democrático sólidamente establecido, como la actual Monarquía constitucional, amplía al máximo los umbrales de la tolerancia y el facilitamiento, sin renunciar por ello a la represión de la disidencia más irreductiblemente violenta ${ }^{6}$.

¿Cómo puede aplicarse este sucinto modelo teórico a las respuestas que dio el régimen franquista a las movilizaciones estudiantiles? Creemos que es posible establecer una conexión entre las estrategias predominantes de control social por parte del Estado y los cuatro períodos significativos en que podría dividirse la historia de la movilización estudiantil durante el franquismo: la posguerra marcada por el auge del Sindicato Español Universitario (SEU) en un intenso ambiente coactivo de impronta fascista. La segunda mitad de los años cincuenta y la primera mitad de los sesenta estuvo caracterizada por el declive del sindicato oficial y los intentos frustrados por impulsar un asociacionismo semioficial, a la par que el régimen abordaba una "normalización" del aparato coactivo estatal mediante la reforma de sus brazos policial, judicial y penitenciario, la progresiva separación del Ejército de las competencias represivas y la construcción de instituciones jurídico-administrativas ad hoc, como el Tribunal de Orden Público (TOP). La etapa posterior a 1968 contempló un incremento de la agitación política en las aulas y un paralelo endurecimiento de la represión estatal y paraestatal, siguiendo las pautas de la doctrina contrasubversiva entonces en boga en el mundo occidental. Por último, en el período 1974-1976 se instaló un marco

\footnotetext{
${ }^{6}$ Tilly, From Mobilization to Revolution, 104-112.
} 
de tolerancia en el ámbito estudiantil que coincidió con el fracasado proyecto de aperturismo político limitado del Gobierno Arias-Fraga.

\begin{tabular}{|l|c|c|}
\hline & Anticipatoria & De respuesta \\
\hline Represión & Tardofranquismo (1968-1973) & Franquismo pleno (1954-1968) \\
\hline Facilitamiento & Posguerra (1939-1954) & Pretransición (1974)-1976 \\
\hline
\end{tabular}

El SEU, milicia y policía de la Universidad totalitaria (1936-1954)

Durante la Guerra Civil, la rama estudiantil de Falange tuvo un crecimiento parangonable al experimentado por otras secciones del partido: se constituyeron 33 sindicatos provinciales y 86 sindicatos locales, que encuadraban un total de 28.367 afiliados, según los datos recopilados para el III Consejo Nacional extraordinario del SEU celebrado en Salamanca el 29 de octubre de 1936:

\begin{tabular}{|l|c|c|}
\hline \multicolumn{1}{|c|}{ Provincia } & Capital & Resto de la provincia \\
\hline Álava & 417 & 32 \\
\hline Ávila & 378 & \\
\hline Badajoz & 129 & \\
\hline Baleares & 238 & 320 \\
\hline Burgos & 398 & \\
\hline Cáceres & 104 & 696 \\
\hline Cádiz & 486 & 427 \\
\hline Córdoba & 715 & 2.807 \\
\hline Coruña & 1.137 & 274 \\
\hline Granada & 320 & 330 \\
\hline Guipúzcoa & 448 & 94 \\
\hline Huelva & 481 & 230 \\
\hline Huesca & 117 & 98 \\
\hline León & 186 & 300 \\
\hline Logroño & 539 & 132 \\
\hline Lugo & 530 & 620 \\
\hline Málaga & 326 & 804 \\
\hline Marruecos & 530 & 46 \\
\hline Navarra & 754 & \\
\hline Orense & 600 & \\
\hline
\end{tabular}




\begin{tabular}{|l|c|c|}
\hline \multicolumn{1}{|c|}{ Provincia } & Capital & Resto de la provincia \\
\hline Oviedo & 358 & 70 \\
\hline Palencia & 438 & 1.170 \\
\hline Pontevedra & 450 & 498 \\
\hline Sevilla & 2.735 & 205 \\
\hline Salamanca & 472 & 100 \\
\hline Segovia & 450 & 194 \\
\hline Soria & 300 & 83 \\
\hline Tenerife & 182 & 180 \\
\hline Teruel & 235 & 352 \\
\hline Toledo & 341 & 352 \\
\hline Valladolid & 1.400 & $\mathbf{1 0 . 4 1 4}$ \\
\hline Zamora & 230 & \\
\hline Zaragoza & 1.520 & $\mathbf{1 7 . 9 5 3}$ \\
\hline TOTAL & & \\
\hline
\end{tabular}

Fuente: "Para antes de conocer la Historia” (apuntes de historia del SEU), en FUE.APSR, caja 58, carp. 2, pp. 23-24

A consecuencia de la unificación política culminada en el Decreto de 19 de abril de 1937, y tras varias reuniones previas, el 12 de octubre de ese año la Agrupación Escolar Tradicionalista (AET), la Federación de Estudiantes Católicos (FEC) y otras agrupaciones estudiantiles de derecha quedaron oficialmente integradas en el SEU, que se vio sometido a una rápida transición desde su modelo original de agitación escuadrista a su oficialización como sindicato único en un tipo de Universidad de marcada impronta totalitaria ${ }^{7}$. Pero, como en el caso de los partidos y las milicias de la zona rebelde,

\footnotetext{
${ }^{7}$ La caracterización del SEU “escuadrista”, en Miguel Ángel Ruiz Carnicer, El Sindicato Español Universitario (SEU) 1939-1965: La socialización política de la juventud universitaria en el franquismo (Madrid: Siglo XXI, 1996), 52-72. Sobre la Universidad de la época, véanse Juan José Carreras Ares y Miguel Ángel Ruiz Carnicer (eds.), La Universidad española bajo el régimen de Franco. Actas del Congreso celebrado en Zaragoza entre el 8 y el 11 de noviembre de 1989 (Zaragoza: Institución Fernando El Católico, 1991); Jaume Claret Miranda, El atroz desmoche. La destrucción de la Universidad española por el franquismo, 1936-1945 (Barcelona: Crítica, 2006); Manuel Juan Farga, Universidad y democracia en España [30 años de lucha estudiantil] (México: Era, 1969); Juan Manuel Fernández Soria y Alejandro Mayordomo Pérez, "En torno a la idea de Universidad en la España de la post-guerra (1939-1943)", en $7^{\text {th }}$ International Standing Conference for the History of Education. Educación superior y sociedad. Perspectivas históricas (Salamanca: Depto. de Historia de la Educación, 1985), II: 249-262; Ricardo Montoro Romero, La Universidad en la España de Franco (1939-1970). Un análisis sociológico (Madrid: CIS, 1981) y Carolina Rodríguez López, La Universidad de Madrid en el primer franquismo: ruptura y continuidad [1939-1951] (Madrid: Ed. Dykinson-Universidad Carlos III de Madrid, 2002).
} 
la unión de las organizaciones estudiantiles no se hizo con la plena aquiescencia de todos los implicados: el día de la unificación forzada, durante una concentración que concentró a la militancia del nuevo sindicato en el campo de La Serna (Burgos), se produjeron graves incidentes entre los representantes de las diversas juventudes escolares: un nutrido grupo de carlistas se negó a desfilar ante Franco porque llevaba camisa azul, pero no boina roja. El desacato se zanjó con el procesamiento de todos los dirigentes de la AET y de algunos jefes del SEU ${ }^{8}$. El jefe nacional de la AET, José María Zaldívar, fue expulsado del partido único y sustituido en su cargo por José María Olazábal. Por Decreto de 21 de noviembre de 1937 (BOE del 23), el nuevo SEU unificado vio aprobado sus Estatutos, que permanecerían en vigor hasta la reforma de 1958. Se le otorgaba el estatus de sindicato único, y, como representante integral de todos los estudiantes españoles, debía velar "porque una disciplina estatal rigurosa de la educación consiga formar en los españoles un espíritu nacional fuerte y unido" (artículo 1, apartado e).

La fusión resultó un proceso tortuoso, y en parte frustrante para todas las organizaciones involucradas. Sometido a fuertes presiones desde el interior del tradicionalismo, Olazábal reclamó al delegado nacional de Cultura, Pedro Sáinz Rodríguez, un reparto virtualmente paritario de los puestos de responsabilidad en el sindicato oficial en ciernes:

Teniendo en cuenta la fuerza numérica de afiliados con que cuenta la AET, que debe estimarse cuando menos como exactamente igual y probablemente mayor a la del SEU, en tanto la ejecución del Decreto de Unificación no nos demuestre lo contrario [...] Creo mi deber suplicar respetuosamente a su Excelencia haga JUSTICIA a las Agrupaciones Escolares Tradicionalistas, las primeras en el puesto de lucha de la Universidad en los albores del resurgimiento patrio, la primera en el tributo de sangre en la hora trágica, pero gloriosa del Alzamiento Nacional, la única que cuenta con una actuación limpia, desinteresada, leal, al misma en todos los tiempos, según estoy dispuesto a demostrarlo documentalmente si fuera preciso, por lo cual pido un pie de igualdad absoluta en los puestos Directivos del nuevo Sindicato que, según creo, han quedado a la libre designación de su Excelencia en la siguiente proporción:

- Jefatura Nacional: SEU de FE de las JONS

- Secretario General: AET

- Jefatura Sección Femenina: SEU de FE de las JONS

- Inspección General: AET

- Tesorería General: AET

${ }^{8}$ David Jato Miranda, La rebelión de los estudiantes. Apuntes para una historia del alegre SEU (Madrid: el autor, 1975), 444-445. Reseñas del acto, convenientemente censuradas, en Arriba España (Pamplona), 13-X-1937: 1 y El Alcázar (Toledo), 14-X-1937: 2. 
De los nueve consejeros que, además de los cargos Nacionales, integran la Junta Consultiva Permanente, cuatro para la AET, cuatro para el SEU y uno para los Estudiantes Católicos, quedando la presidencia para la AET ya que la Jefatura Nacional y por tanto la presidencia del Consejo Nacional quedan para el SEU. Por lo cual propongo para los cargos que estimo que en justicia nos corresponden, a los siguientes señores:

- Secretario General: Elías Sánchez Marco

- Tesorero General: Luis Urbano

- Consejeros de la Junta Consultiva Permanente: Pedro Ma Gómez Ruiz, Juan Carlos Villacorta Luis, Alfonso González Quintela, José Manuel de Ibieta-Torre Mendía, quedando para mí la Inspección General y la Presidencia de la Junta Consultiva Permanente.

Olazábal concluía su escrito con una rotunda afirmación, que sonaba a amenaza: "Nunca pactaremos en condiciones de inferioridad, que no admi-

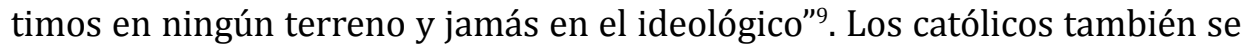
dispusieron a ejercer su influencia: en su pastoral de 10 de marzo de 1938, el primado Isidro Gomá defendió de forma explícita el sindicalismo estudiantil católico, y fue apoyado por los obispos de Sevilla y Santiago. El 29 de junio de ese año, obtuvo del ministro de Educación Nacional la garantía de que el estatuto del estudiantado católico no se alteraría sin mediar una consulta previa a los obispos. Pero, a la hora de la verdad, ni los carlistas ni los católicos recibieron un trato proporcional al peso que sus formaciones escolares habían tenido antes de la guerra. Los días 20 y 21 de septiembre de 1939 se celebró una reunión de la FEC presidida por un representante de Gomá, quien obligó a disolverla en el contexto del inminente Decreto de 23 de septiembre de 1939 (BOE de 9 de octubre), que confirmaba oficialmente el monopolio falangista con la absorción y disolución del resto de las asociaciones de carácter estudiantil ${ }^{10}$. El hecho de que el SEU adquiriera carácter único y oficial, no de entidad competidora con otras organizaciones estudiantiles de derecha, produjo un incremento del malestar campante entre las distintas tendencias que convivían en el nuevo organismo sindical teóricamente unificado. Mientras los carlistas pugnaban por mantener su simbología y sus propios locales, en el marco de una reorganización semiclandestina de la AET que se extendió

${ }^{9}$ José María de Olazábal a Pedro Sáinz Rodríguez (Bilbao, 17-XII-1937), en FUE.APSR, leg. PSR1/13-444.

${ }^{10}$ Véanse Guy Hermet, Los católicos en la España franquista, II: Crónica de una dictadura (Madrid: CIS-Siglo XXI, 1986), 130 y Feliciano Montero García, "De la JUMAC a la JEC. Aproximación a la historia de la AC estudiantil”, en Feliciano Montero (coord.), Juventud Estudiante Católica (1947-1997) (Madrid: JEC, 1998), 21-71. 
por Madrid y Valencia ${ }^{11}$, los católicos trataron de sortear la homogeneización estudiantil con una reforma de los estatutos de la Acción Católica Española, por la que se reglamentaron las "especializaciones" obrera y universitaria. Este proceso se realizó en medio de una fuerte tensión entre Franco y Gomá, motivada por la censura oficial sobre la pastoral del primado Lecciones de la guerra y tareas de la paz, fechada el 1 de septiembre de 1939. El texto reivindicaba los derechos y las libertades de la Iglesia y criticaba veladamente el criterio totalitario del Estado, que pretendía unificar todas las instituciones fundadas en el derecho natural. Incluso se permitía denunciar la presunta influencia masónica en el SEU y el Sindicato Español de Magisterio (SEM). Con todo, parece que la cuestión estudiantil pudo encauzarse gracias a las conversaciones que mantuvo el cardenal con el ministro secretario general de FET, general Agustín Muñoz Grandes, en el sentido de respetar la FEC como entidad de derecho eclesiástico, lo que permitiría su supervivencia formal, aunque sus miembros deberían estar integrados asimismo en el SEU ${ }^{12}$.

El monopolio incontestado del SEU en las aulas fue uno de los jalones básicos de la transformación totalitaria de la Universidad española. En el transcurso de su IV Congreso Nacional Extraordinario, celebrado en El Escorial del 4 al 8 de enero de 1940, se produjo la fusión definitiva de carlistas, católicos y falangistas. También se discutió sobre la sindicación obligatoria, la milicia universitaria y la orientación profesional, y sobre conceptos clave como revolución y generación. Aunque se señaló que "el SEU va a la cabeza de la generación revolucionaria”, y se exigió la renovación del sistema político bajo premisas totalitarias, se produjeron enconados debates sobre el alcance de la sindicación obligatoria, que de hecho ponía al SEU en manos del Estado. La unificación trastocó la autopercepción de juventud universitaria falangista como "vanguardia revolucionaria del partido" que, conjugando estudio y acción, luchaba por evitar la "rebarbarización de España"13. Se avecinaba una nueva etapa, marcada por la tensión entre el activismo revolucionario de los años de la República y la burocratización forzada como instrumento de encuadramiento coercitivo de la juventud escolar el seno del Nuevo Estado franquista. Según el jefe nacional del SEU, José Miguel Guitarte Irigaray, la ac-

${ }^{11}$ Manuel de Santa Cruz (seud. de Alberto Ruiz de Galarreta), Apuntes y documentos para la historia del tradicionalismo español, volumen 1 (Madrid: La Editorial Católica, 1979), 166-167.

${ }^{12}$ Miguel Ángel Dionisio Vivas, "La prohibición de la carta pastoral 'Lecciones de la guerra y deberes de la paz' y los conflictos entre la Iglesia y el Gobierno español en el otoño de 1939", Toletana 20 (2008): 95.

${ }^{13}$ José Miguel Guitarte, Discursos y escritos en una etapa del SEU (Madrid: Eds. Haz, 1941), 31. 
tividad del sindicato falangista, cuya primera generación de militantes había desaparecido prácticamente durante la guerra, se manifestaría en lo sucesivo de tres maneras: "formación política, formación profesional y formación militar, con el fin de dotar a la Milicia y al Ejército de un cuadro de excelentes oficiales capaces y útiles para el futuro. La formación política se hará de tal manera que los estudiantes estarán perfectamente preparados, doctrinaria y socialmente, para llenar toda clase de funciones en el partido y en la vida"14. La compaginación de estudio y acción implicaba una auténtica militarización de sindicato estudiantil:

En FET y de las JONS compete a las milicias todo lo relativo a la organización militar. El SEU tendrá un enlace con la Jefatura Nacional de Milicias y otros con las Jefaturas Provinciales y Locales de éstas, siempre y cuando que en la zona de jurisdicción de la misma existan centros docentes. El estudiante no formará en las unidades milicianas de su lugar de residencia ni estará mezclado con otros milicianos de procedencias no estudiantiles. En tanto no terminen sus estudios, estarán afectos a una unidad miliciana formada por sus compañeros de estudio y sólo por éstos. Esa unidad (Falange, Centuria, Bandera, etc.) se integrará dentro de otra superior de la que vendrá a ser una parte más. Se procurará reunir en una sola unidad todas las formadas en una localidad por elementos del SEU. Este criterio no será aplicable a la provincia o región dado el carácter local de las milicias. Estas unidades no tendrán nombre ni distintivo especial alguno (serán la centuria tal de la bandera tal, y la bandera tal de cual tercio) y así no se romperá la unidad miliciana de la Falange. Todo estudiante universitario o de escuelas especiales habrá de formarse como futuro jefe para prestar servicio en la escala de reserva [...] En verano se hará instrucción colectiva y prácticas de conjunto en campamentos de sierra, campo o playa, y con duración por lo menos de un mes. Los que efectúan estudios de tres o cuatro años saldrán nombrados Alféreces de reserva y Jefes de Centuria. Los que efectúen estudios de cinco o más años saldrán tenientes de la Escala de Reserva y Jefes de Bandera [...] Los Jefes Subalternos de Jefes de Centuria para abajo, de las unidades del SEU, se nombrarán entre los alumnos de éste de los últimos cursos o entre jefes procedentes del SEU, aunque ya cesaran sus estudios ${ }^{15}$.

Mediante la Ley de Ordenación Universitaria (LOU) de 29 de julio de 1943 se reconoció al SEU su condición de "órgano universitario" tanto en la Universidad como en las distintas facultades (a excepción de las Escuelas Técnicas), y la obligatoriedad de afiliación al mismo para quienes quisieran acceder a la formación superior, así como para obtener becas. El artículo 35 de la Ley confirmaba la existencia de una Milicia Universitaria que facilitaba el servicio militar obligatorio a los estudiantes y proporcionaba al

\footnotetext{
${ }^{14}$ Arriba (Madrid), 13-VIII-1940, cit, por Farga, Universidad y democracia, 37.

15 "Para antes de conocer la Historia" (apuntes de historia del SEU, s.f.), en FUE.APSR, caja
} 58 , carp. 2. Se incluye un prolijo plan de cátedras militares por armas en los centros docentes. 
Ejército la necesaria oficialidad de complemento, al tiempo que los escolares se adoctrinaban en los principios y los valores castrenses.

Esta irrupción totalitaria se hizo en una Universidad destruida física y moralmente por la represión de la guerra y la posguerra, y con un alumnado significativamente inferior al de los años republicanos. La imposición coactiva de los nuevos símbolos y mitos fue uno de los rasgos característicos de la nueva situación. Como recuerda un estudiante catalán:

Al principio de cada clase, todos los estudiantes, en pie, saludaban brazo en alto al profesor que entraba. Sólo cuando éste había contestado el saludo, podían sentarse los disciplinados - y gimnásticos, de tanto repetirlo diversas veces al día- alumnos. En todas las aulas había, a la izquierda de la tarima del catedrático, la silla del estudiante caído, con una bandera española pintada en el respaldo. Y más de un estudiante no caído fue furiosamente agredido por haber intentado sentarse ${ }^{16}$.

El SEU mantuvo el control político de los estudiantes mediante el terror, aplicándose como antaño en intimidaciones, palizas, multas, cortes de pelo al cero, quema de libros o destrozos de símbolos de ideología adversa. Los delegados de curso, nombrados por el delegado de Facultad y éste por el jefe del SEU del Distrito Universitario, tenían que llevar un fichero de sus compañeros en el que se hacía constar su comportamiento, capacidad académica, ideario político, actitud moral, espíritu y carácter personal ${ }^{17}$. Las agresiones a profesores (como el catedrático tradicionalista de Derecho Francisco Elías de Tejada en Salamanca en abril de 1944 y el primorriverista José de Yanguas Messía en Madrid en febrero de 1946) ${ }^{18}$ o los enfrentamientos entre grupos estudiantiles rivales (hubo choques entre miembros del SEU y la AET carlista en la festividad de los Mártires de la Tradición el 10 de marzo de 1949) y con otros colectivos de marcada identidad corporativa (como los incidentes entre cadetes y estudiantes en Zaragoza que llevaron a la declaración de una huelga escolar en febrero de 1956), quedaban a mitad de camino entre la tradicional "jarana estudiantil" y el matonismo fascista. El talante agresivo del sindicato falangista trató de mantenerse con el fomento de actitudes y valores de impronta castrense. Era preciso "inculcar en

${ }^{16}$ Josep Maria Colomer i Calsina, Els estudiants de Barcelona sota el franquisme (Barcelona: Curial, 1978), I, 25.

${ }^{17}$ Elena Hernández Sandoica, Miguel Ángel Ruiz Carnicer y Marc Baldó Lacomba, Estudiantes contra Franco (1939-1975). Oposición política y movilización juvenil (Madrid: La Esfera de los Libros 2007), 82.

${ }^{18}$ José María Gil Robles y Quiñones, La Monarquía por la que yo luché. Páginas de un diario (1941-1954) (Madrid: Taurus, 1976), 87 y 165. 
nuestras juventudes los viejos y eternos principios del honor, de la lealtad y de la disciplina militares", con el fin de que "lleguen al Ejército español en los momentos que la Patria lo exija"19. La creación de la Milicia Universitaria según la Ley de 2 de julio de 1940 (BOE no 190 de 8 de julio) incrementó la militarización de las aulas, y otorgó una posición de privilegio a los estudiantes universitarios con pasado o vocación combatiente.

Por Decreto de la Jefatura del Estado de 4 de octubre de 1942 (BOE $\mathrm{n}^{\circ}$ 303 del 30), la Milicia Universitaria acabó por reciclarse en un sistema de Instrucción Premilitar Superior encargado, entre otras tareas, de prestar auxilio a las autoridades académicas en el mantenimiento del orden y la disciplina en el interior de los recintos escolares. El procedimiento de actuación que contemplaba la normativa mostraba a las claras la función coactiva que se asignaba a la milicia del SEU: "Los que en el interior de la Universidad alteraran la normalidad escolar serán puestos por la Milicia Universitaria a disposición de su jefe de día, quien acordado su arresto, lo pondrá inmediatamente en conocimiento de la autoridad académica y del Jefe Provincial del movimiento" 20 . Esta exaltación, del más puro "vigilantismo", se mantuvo hasta el extremo de que, en el V Consejo Nacional del SEU celebrado en Alcalá de Henares en diciembre de 1941, se proclamó que la Milicia Universitaria debía ser el arma más eficaz para desenmascarar a los traidores y enemigos de Falange ${ }^{21}$. De modo que tras 1942, la dirección del SEU aceptó los requerimientos del régimen franquista con todas sus consecuencias, actuando como una especie de "policía universitaria paralela" y como apoyo coreográfico del régimen ${ }^{22}$.

Entendido como la cantera de la élite dirigente del régimen, los responsables del SEU estaban sometidos a una rigurosa selección académica e ideológica, mezcla de estudio y acción, con la esperanza de alcanzar el poder político tras un relevo generacional que nunca se produjo, y que acabó por reducir su función política al poco honroso papel de "policía de la Universidad" a través de una intensa despolitización de la mayoría estudiantil que se hizo evidente a partir de los años cincuenta.

${ }^{19}$ Guitarte, Discursos y escritos, 56.

${ }^{20}$ Art. 2 del Decreto de 4-X-1942, cit. por Sergio Vilar, Historia del antifranquismo, 19391975 (Esplugues de Llobregat: Plaza \& Janés, 1984), 172.

${ }^{21}$ La Falange ante la Universidad. Discursos y conferencias del $V$ Consejo Nacional del SEU (Alcalá de Henares, 1941) (Madrid: SEU-Taller Gráfico Marsiega, 1942), 94 y ABC (Madrid), 11-XII-1941: 10, cit. por Fernández Soria y Mayordomo Pérez, "En torno a la idea de Universidad", 254.

${ }^{22}$ Salvador Giner, "Universitat, moviment estudiantil i poder polític a l'Estat espanyol, 1939-1975", Aïnes 2 (diciembre 1975): 71. 


\section{Los sucesos de 1956 y la crisis del modelo de encuadramiento burocrático}

Tres lustros después de su constitución como sindicato único escolar, el SEU continuaba manteniendo un papel central en la Universidad, a pesar de la creciente alienación de la masa estudiantil en el sentido de apatía y conformismo. Ello explica el rechazo creciente a su papel como instrumento de encuadramiento político y la creciente respuesta represiva del Estado cuando este modelo universitario entró en crisis a mediados de los cincuenta, momento en que se consumó la ruptura entre la juventud universitaria y el régimen, y nació un movimiento estudiantil democrático que marcó el principio del fin de la Dictadura.

El Congreso Nacional del SEU celebrado del 10 al 17 de abril de 1953 había adoptado un embrión de carta de derechos bajo la forma de un Estatuto del Estudiante. Este Estatuto, puesto en vigor a partir del 11 de agosto, desarrollaba algunos aspectos de la LOU de 1943: el estudiante debía participar "muy principalmente en la misión de llevar al resto de los españoles los bienes de la cultura, la alegría, la milicia, la salud y el deporte", todo ello a través del SEU. Pero también mantendría "tareas de vigilancia y cumplimiento de los preceptos y reglamentos de ordenación académica" ${ }^{23}$. El SEU conservaba el monopolio del control de los escolares, pero bastó un atisbo de disidencia para que el encuadramiento paternalista dejara paso a la represión. El 26 de enero de 1954, con ocasión de la movilización en pro del "Gibraltar Español", orquestada por FET como respuesta a la visita de la reina Isabel II al peñón, se desencadenaron inesperadas cargas policiales contra los estudiantes, que marcharon en manifestación airada hasta la Puerta del Sol y tomaron la emisora Radio Madrid, ubicada en la Avenida de José Antonio (actual Gran Vía). Tras un asalto de las fuerzas de seguridad al caserón de San Bernardo, al día siguiente se organizó una asamblea de protesta que congregó a 2.000-3.000 estudiantes, que acordaron denunciar en un comunicado la manipulación de la que habían sido objeto, y convocar dos días de huelga para protestar contra la brutalidad policial ${ }^{24}$. El día 28, los escolares apedrearon el Ministe-

${ }^{23}$ Cit. por Juan Luis Rubio Mayoral, Disciplina y rebeldía: los estudiantes en la Universidad de Sevilla (1939-1970) (Sevilla: Secretariado de Publicaciones, Universidad de Sevilla, 2005), 75-76.

24 "Los estudiantes madrileños hemos sido utilizados como cabeza de turco" (s.f., pero II-1954), en AH.PCE, Intelectuales, movimiento estudiantil, jacket 62. Otra octavilla sobre la Universidad y el SEU (X-1954), en AH.PCE, Nacionalidades y regiones, Madrid, jacket 782. Sobre estos incidentes, véanse José Álvarez Cobelas, Envenenados de cuerpo y alma. La oposición universitaria al franquismo en Madrid (1939-1970) (Madrid: Siglo XXI, 2004), 68-69; Hernán- 
rio de Justicia, y la Policía contestó con disparos. El SEU, que había perdido claramente el control de la situación, difundió hojas anónimas en las que se pedía la destitución del ministro secretario nacional del Movimiento José Luis Arrese, del jefe nacional del SEU Jorge Jordana, del ministro de la Gobernación Blas Pérez y el director general de Seguridad Rafael del Hierro ${ }^{25}$. El desenlace de la crisis fue una dimisión colectiva de los cuadros del SEU, cuya Primera Línea protagonizó el 9 de febrero un incidente con el secretario general del partido Raimundo Fernández Cuesta con ocasión del homenaje anual al "estudiante caído" Matías Montero. La Policía Armada patrulló por los barrios obreros de Pacífico, Cuatro Caminos y Ventas por temor a una improbable confluencia de las manifestaciones estudiantiles con el malestar de la clase trabajadora.

La crisis de la representación estudiantil oficial alcanzó su momento culminante en febrero de 1956, cuando tras la convocatoria de dos Congresos Nacionales de Estudiantes al margen del SEU y la amenaza de celebración de elecciones libres en las Facultades del Distrito Universitario de Madrid, la sede universitaria de San Bernardo fue asaltada el 7 de febrero por la XX Centuria "Alejandro Salazar" de la Guardia de Franco, unidad paramilitar fundada en 1949 y constituida preferentemente de miembros de la "vieja guardia" del SEU intensamente politizados, como Diego Márquez Horrillo, jefe de la Primera Línea del SEU a fines de los años cuarenta y secretario general del Sindicato desde 1954. Como en épocas pasadas, estos asaltos protagonizados en buena parte por actores ajenos a la normal actividad académica fueron sentidos por los estudiantes como un ataque externo, y tuvieron la virtualidad de aumentar su cohesión interna y señalar con claridad un enemigo contra el que dirigir la hostilidad del colectivo. En la mañana del 8, los estudiantes de Derecho se declararon en huelga para protestar por la agresión del día anterior, y expulsaron a los matones falangistas del recinto de San Bernardo, El 9 hubo una manifestación de protesta desde San Bernardo a la Puerta del Sol y la Ciudad Universitaria que se encontró con una manifestación oficial falangista en honor al "estudiante caído" Matías Montero que enfilaba el bulevar de Alberto Aguilera hacia la Universidad. En el

\footnotetext{
dez Sandoica, Ruiz Carnicer y Baldó Lacomba, Estudiantes contra Franco, 115-121; Fernando Jáuregui y Pedro Vega, Crónica del antifranquismo (Barcelona: Argos Vergara, 1983-1984) I, 170-172; Pedro Laín Entralgo, Descargo de conciencia (1930-1960) (Barcelona: Instituto de Estudios Turolenses/Galaxia Gutenberg/Círculo de Lectores, 2003), 374-376 y Ruiz Carnicer, El Sindicato Español Universitario, 286-290.

${ }^{25}$ Carta de Ricardo Muñoz Suay a "queridos amigos" (11-II-1954), en AH.PCE, Intelectuales, movimiento estudiantil, jacket 80.
} 
cruce con Guzmán el Bueno se encontraron con los estudiantes que habían subido por San Bernardo, haciendo inevitable un encontronazo en el que quedó gravemente herido el falangista Miguel Álvarez Pérez, de la Centuria "Sotomayor" de las Falanges Juveniles de Franco del Frente de Juventudes de Madrid. Acudieron los guardias, y a palos y con mangueras de agua disolvieron las concentraciones. El Gobierno ordenó el cierre de la Universidad por dos semanas y promulgó el primer Decreto-Ley de posguerra suspendiendo por tres meses los artículos 14 y 18 del Fuero de los Españoles (residencia y habeas corpus). Las octavillas que rezaban "abajo el SEU" y "abajo Blas Himmler" mostraban la evidente pérdida de consideración de la Falange y del Gobierno ante la opinión pública. La drástica reacción oficial a la agitación estudiantil contribuyó a hacer de esa rebelión un problema político de primer orden, y a extender la conflictividad a otros sectores.

La represión de respuesta, siempre a remolque de la creciente movilización de la protesta estudiantil, trató de ser modulada durante la década siguiente con estrategias más conciliadoras, como el fomento de un asociacionismo profesional de carácter oficial y pretendidamente apolítico (las Asociaciones Profesionales de Estudiantes o APEs), cuyo fracaso definitivo, que coincidió con las "tormentas del 68", dejaría vía libre en los campus a la mayor oleada de violencia estatal y paraestatal desde la posguerra.

La estrategia del palo y la zanahoria: entre la persecución administrativa y el asociacionismo tolerado (1956-1967)

Entre 1956 y 1965, la actividad opositora permaneció a la defensiva, enfrascada en la lucha interna por el control del sindicato oficial hasta que su ruptura y declive permitió plantear la lucha abierta a través del sindicalismo unitario, democrático y centralizado de los sindicatos democráticos de estudiantes universitarios (SDEU).

Un nuevo punto de no retorno en la historia del movimiento universitario antifranquista lo marcaron la IV Asamblea Libre de Madrid del 18 al 22 de febrero y la manifestación del 24 de febrero de 1965 en la capital. La dinámica de la protesta fue muy similar a la desencadenada durante la III Asamblea Libre de Estudiantes del año anterior: el 17 de febrero, y bajo el patrocinio de la Federación Universitaria Democrática Española (FUDE, plataforma sindical democrática, federal e independiente sobre la base de los estudiantes democristianos, socialistas y sindicalistas) y la Unión de Estudiantes Demócratas (UED, de carácter democristiano) se organizó en la 
Universidad de Madrid una "Semana de la Paz", con un ciclo de conferencias titulado "Hacia una verdadera paz, hoy" que exacerbó la suspicacia del régimen embarcado en la campaña de los XXV Años de Paz y que fue vetado por el decano de la Facultad de Ciencias. La prohibición de estas conferencias de la oposición semitolerada por parte de la autoridad académica llevó a la convocatoria de la IV Asamblea Libre de Estudiantes de la Universidad de Madrid (tras las que tuvieron lugar en 1956, 1962 y 1964) en el aula magna de la Facultad de Ciencias. Con el apoyo de seis mil escolares, parte del profesorado y algunos catedráticos, la reunión fue un gran éxito, y en sus conclusiones finales se solicitó una vez más la sindicación libre, al margen de las directrices del Movimiento, y la disolución del SEU ${ }^{26}$. El 24 de febrero, unos 5.000 estudiantes firmaron un pliego de peticiones que reclamaba la implantación de un sindicato libre, autónomo y representativo; la amnistía total para los catedráticos y estudiantes expedientados; la libertad de expresión docente y discente; la solidaridad con los obreros y la declaración del 2 de marzo como Día del Estudiante Libre, en réplica al falangista "Día del Estudiante Caído". También se acordó realizar una marcha para entregar el documento de conclusiones a las autoridades académicas. Al encaminarse con José Luis López Aranguren, Agustín García Calvo y otros profesores hacia el Pabellón de Gobierno de la Universidad, la comitiva formada por unos 6.000 estudiantes protagonizó una sentada y fue dispersada a manguerazos y a golpes por la Policía Armada, que provocó veinte heridos de consideración y un centenar de heridos leves además de practicar la detención de treinta estudiantes y cuatro profesores.

El 28 de febrero, el vicesecretario general del Movimiento, Fernando Herrero Tejedor, daba comienzo a la respuesta gubernamental con la presentación a los jefes provinciales del partido único de una auténtica batería de medidas represivas:

1ํ: Afrontar los acontecimientos con mucha firmeza y energía, sin ninguna muestra de debilidad, principalmente en las medidas más eficaces, que no son precisamente las que puede adoptar la fuerza pública; $2^{\circ}$ : Impedir que en los Colegios Mayores o en las aulas universitarias se den conferencias o seminarios o coloquios por los profesores conocidamente enemigos del régimen; 3o: Evitar la neutralización de las autoridades académicas, poniendo al frente de las universidades a profesores con criterio político firme; 4o: Provocar la reacción lógica de los padres de familia de cuya confianza se abusa, al deformar la mentalidad de sus hijos en una línea abiertamente hostil al

${ }^{26}$ Información de la Oficina de Información Diplomática a France Press (25-II-1965) sobre la "Asamblea Libre de Estudiantes" celebrada en la Facultad de Filosofía y Letras de Madrid y otras asambleas clandestinas en la Universidad, en AJRG, caja 396, carp. 19. 
orden constituido; 5: Utilizar entidades y asociaciones para que muestren su repulsa a los hechos y especialmente a la actitud de los catedráticos: asociaciones familiares, alféreces provisionales, entidades profesionales, excombatientes, corporaciones, etc., y excitar la actitud de la prensa para que mantenga una información constructiva en esta línea; 6으: Afrontar sin demora una nueva regulación de la estructura del SEU en la Universidad; 7: Establecer un plan interno de formación en los Colegios Mayores de toda clase, a cargo de catedráticos de confianza; 8: Adoptar medidas de aplicación rigurosa de la legislación fiscal, sobre las personas que se hayan destacado en la actividad subversiva, y privarlas de concesiones graciables de que algunas de ellas gozan; 9: Imponer con todo rigor las sanciones académicas que se hayan hecho acreedores los catedráticos y extenderla a algún otro cuya solidaridad y actuación es también patente (Aguilar Navarro mandó una carta a la Asamblea Libre del día 25, lo que muestra su organización anticipada, y asistió a la Asamblea Libre del día 25 donde dijo: 'Ningún régimen sin ideología puede mantenerse, y este régimen no la tiene. Ante la debilidad de que ya da muestras, aprestemos a darle el empujón final'); 10: Aplicar a rajatabla el reglamento académico, en cuanto a asistencia a clase, cumplimiento por parte del profesorado, faltas a la disciplina, exámenes, prolongación de curso, etc.; 11: Desarticular a los dirigentes de los grupos más extremistas, especialmente la FUDE, y mantener una información rápida y adecuada dentro de las propias estructuras estudiantiles; 12: Realizar una amplia campaña de información con los medios de que dispone el Estado para aclarar la situación y orientar suficientemente a la opinión pública sobre ella; 13: Divulgar, al menos en ciertos niveles, las fichas de algunos de los catedráticos instigadores, Por ejemplo, el Sr. García Calvo, según es público y notorio, suele hacer entre sus alumnos la apología del suicidio, es partidario del amor libre, ha tenido en varias ocasiones dificultades serias por su actuación con alguna alumna, parece que en la actualidad sigue con una ex-alumna que vive con él. Se jacta de hacer sacrificios de palomas al dios Duero. En Sevilla, de donde procede, es perfectamente conocido y estos datos se conocen muy ampliamente ${ }^{27}$.

Desbordado por los sucesos, y reconociendo las consecuencias contraproducentes de las represalias, el Gobierno decidió negociar directamente con los estudiantes opositores. El presidente de las Cortes, Esteban Bilbao, se declaró dispuesto a reformar la vetusta LOU, mientras que en la prensa aparecían artículos que invitaban a la búsqueda de una mediación. Durante los días 7 a 9 de marzo, Herrero Tejedor se reunió en su casa de Villacastín con nueve representantes de la oposición universitaria al margen del SEU para negociar una salida a la crisis. En realidad, Herrero trataba de ralentizar y dividir el movimiento asambleario que se estaba extendiendo como un in-

${ }^{27}$ Carta de Fernando Herrero Tejedor a los jefes provinciales del Movimiento (Madrid, 26II-1965) en AFPI, AJMAH, caja 800-10. El 3-IV, tras sus "diálogos" con los representantes estudiantiles en Villacastín, se hizo pública esta misiva a los gobernadores civiles con instrucciones para la represión. Una información de Le Monde sobre algunas actividades universitarias clandestinas y sobre la actuación represiva del ministro de Información y Turismo, Manuel Fraga, en la crisis estudiantil de 1965, en AJRG, caja 396, carp. 19. 
cendio a otros distritos universitarios, y conseguir que los delegados elegidos en octubre adoptaran posturas más conciliadoras. El Decreto de 5 de abril de 1965 (BOE de 7 de abril) hizo desaparecer el sindicato estudiantil falangista, transformándolo en una estructura amorfa, dividida por ramas en Asociaciones Profesionales de Estudiantes (APEs), "de acuerdo con la legalidad y las organizaciones existentes". Se buscaba así dividir al movimiento democrático en ciernes recompensando las actividades menos comprometidas de carácter semioficial, y reprimiendo con toda energía las manifestaciones de disenso más politizadas. El conjunto de las APEs integraría el SEU, entidad corporativa tutelada por el Estado como "cauce de promoción de los intereses profesionales de los estudiantes" (artículo 3). La transformación del otrora potente entramado escolar falangista en una anodina Delegación-Comisaría General para meros asuntos de servicio, que aún sobrevivió vegetando hasta enero de 1970, supuso su liquidación como organismo de encuadramiento y representación de los estudiantes, y su virtual desaparición de la Universidad.

El incremento de la protesta estudiantil condujo a una proliferación de opciones políticas contestatarias que, a su vez, fue respondida por una diversificación de las funciones coactivas, tanto estatales como paraestatales. El incremento de la represión orquestada desde los ministerios de Justicia, Gobernación y Educación y Ciencia se tradujo en la intervención permanente de la fuerza pública en los campus y en la aplicación rigurosa del reglamento disciplinario en las aulas. Junto a la represión académica, desplegada a través de expedientes, sanciones y expulsiones, figuraba la acción específicamente policial, que incluía la vigilancia de los "grises" y de la Brigada Político Social -BPS - en los lugares habituales de reunión de la comunidad escolar ${ }^{28}$. A ella se añadían la acción perturbadora de confidentes y agentes provocadores, las cargas, golpes, detenciones, torturas, malos tratos, encarcelamientos e incluso muertes sospechosas, como la del estudiante maoísta Rafael Guijarro Moreno, que se arrojó el 30 de enero de 1967 desde la ventana de su casa cuando iba a ser detenido por la BPS. La represión judicial se efectuó a través del TOP, que entre 1964 y 1976 aplicó 7.417 penas a 6.748 condenados, la

${ }^{28}$ Un caso notorio fue el asedio y asalto policial que se produjo el 9/11-III-1966 contra el convento de Capuchinos de Sarriá, donde se estaba celebrando la Asamblea Constituyente del Sindicato Democrático de Estudiantes del Distrito de Barcelona. Sobre la "Caputxinada", véanse Colomer i Calsina, Els estudiants de Barcelona, I, 229-240; Joan Crexell i Playà, La caputxinada (Barcelona: Edicions 62, 1984), 47-82; Farga, Universidad y democracia, 84-90; Hernández Sandoica, Ruiz Carnicer y Baldó Lacomba, Estudiantes contra Franco, 242-247; Gregorio Valdevira González, La oposición estudiantil al franquismo (Madrid: Síntesis, 2006), 80-88 y Vilar, Historia del antifranquismo, 347-352. 
mayor parte jóvenes de 18 a 30 años, y en un $22 \%$ estudiantes ${ }^{29}$. La coacción extraoficial también se manifestó en el despliegue vigilante de nuevos grupos universitarios de extrema derecha, que actuaron en estrecho contacto con la Policía, la cual mantenía en las aulas desde fines de 1960 a agentes encubiertos pagados por la DGS ${ }^{30}$. Pero también surgieron grupos falangistas abiertamente disidentes como el Frente de Estudiantes Sindicalistas (FES) organizado en 1963 bajo la inspiración de Sigfredo Hillers de Luque, que hizo su aparición pública el 1 de abril de 1964 con un manifiesto "A todos los estudiantes" en el que renegaba del SEU oficialista, asumía la herencia del SEU republicano y proponía un modelo de sindicato único, libre, democrático y representativo, lo que le granjeó la hostilidad de otros grupos de la extrema derecha estudiantil como la Defensa Universitaria, grupo "ultra" creado en Madrid durante el curso 1963-1964, y vinculado al movimiento nacional-revolucionario Jeune Europe de Jean Thiriart ${ }^{31}$.

Fracasada la maniobra dilatoria de las APEs, el Gobierno optó por una política de mayor dureza, que dificultara la vertebración y la expansión del movimiento estudiantil democrático: un Decreto promulgado el 3 de mayo de 1967 trató de controlar más estrechamente a los estudiantes, al exigir al profesorado que pasara lista a los alumnos oficiales, fijara un máximo de faltas de asistencia, estableciera un tope de cuatro convocatorias por asignatura y restringiera el derecho de los alumnos libres a asistir a clase y a participar en la vida universitaria Otro Decreto suprimió las prórrogas militares y la posibilidad de realizar la modalidad de Milicias Universitarias a los estudiantes que no observasen "buena conducta académica y ciudadana". Inmediatamente, la Policía inició una nueva campaña represiva, que llevó al desmantelamiento de las delegaciones de alumnos de varias facultades. En esa época resultaban moneda corriente las redadas nocturnas de la BPS para detener en sus domicilios a los representantes estudiantiles o a los que habían participado activamente en asambleas o manifestaciones, que pasaban luego a ser juzgados por el TOP. Esta persecución, que iba acompañada

\footnotetext{
${ }^{29}$ Juan José del Águila Torres, El TOP. La represión de la libertad (1963-1977) (Barcelona: Planeta, 2001), 230.

${ }^{30}$ Informe sobre el Cuerpo General de Policía dentro de la Universidad (XII-1960), en AH.PCE, Intelectuales, movimiento estudiantil, jacket 282. Al parecer, la BPS solicitó doscientos voluntarios entre los policías-alumnos que tuvieran entre 18 y 20 años de edad para matricularse en la Universidad de Madrid.

${ }^{31}$ Francisco Blanco Moral, "El Frente de Estudiantes Sindicalistas: Una manifestación de la oposición falangista al régimen de Franco", Espacio, Tiempo y Forma, Serie V: historia Contemporánea III, no. 2 (1990): 204. Entre los animadores del "FES de Bachiller" a fines de los sesenta se encontraba José María Aznar.
} 
frecuentemente de torturas durante la detención y otras arbitrariedades administrativas, provocó la indignación de las familias y la evolución de importantes sectores de las clases medias hacia un pensamiento más democrático y crítico con el sistema ${ }^{32}$.

\section{La protesta universitaria entendida como subversión (1968-1973)}

Los sucesos de alcance internacional acaecidos en la primavera de 1968 pusieron de manifiesto que las innovaciones tácticas en la protesta estudiantil, y su convergencia con otros movimientos sociales, conducían a choques cada vez más violentos con otros grupos rivales y con las instituciones represivas del Estado. Si en la Europa Occidental, los regímenes democráticos lograron canalizar la mayor parte de la movilización hacia los viejos y nuevos movimientos sociales de alcance sectorial (antimilitaristas, pacifistas, feministas, vecinales, ecologistas, de solidaridad internacional, etc.), en España se alcanzó el paroxismo de la movilización antidictatorial, seguido de un rápido declive donde la celebración compulsiva de asambleas "libres" y la aparición de grupúsculos activistas de naturaleza netamente política dificultaron la posibilidad de reactivación de la protesta organizada.

El incremento de la agitación llenó de inquietud al Gobierno hegemonizado por los tecnócratas, algunos de cuyos miembros estaban persuadidos de que la Universidad estaba sumida en abierta crisis y subversión ${ }^{33}$. Según López Rodó, a inicios de 1968, mientras que el ministro de Educación Emilio Lora Tamayo era partidario de la conciliación, el de la Gobernación Camilo Alonso Vega "quería mantener medidas enérgicas para mantener el orden en el campus de la Complutense" ${ }^{34}$. El 10 de enero de 1968 entró en servicio en las facultades la nueva Policía de Orden Universitario, en teoría al servicio de decanos y rectores, pero en la práctica a las órdenes de la autoridad gubernativa. Su presencia generó nuevos incidentes en febrero, con sentadas de protesta de los estudiantes y asaltos de la Policía Armada a las facultades donde se celebraban asambleas. También proliferaron las querellas de pa-

${ }^{32}$ José María Mohedano, "Una década de lucha en la Universidad", en Historia del franquismo. Franco, su régimen y la oposición (Madrid: Diario 16, 1985), II, 695. La represión contra la constitución del SDEU de Madrid, en carta acerca del desarrollo del curso académico en la Universidad de Madrid (28-V-1967), en AH.PCE, Intelectuales, movimiento estudiantil, jacket 246.

${ }^{33}$ Pere Ysàs, Disidencias y subversión. La lucha del régimen franquista por su supervivencia, 1960-1975 (Barcelona: Crítica, 2004), 17.

${ }^{34}$ Laureano López Rodó, Memorias (1) (Barcelona: Plaza \& Janés-Cambio 16, 1990), 266. 
dres de estudiantes en contra de la Policía por malos tratos y violación del habeas corpus, ya que los agentes acostumbraban a enviar a los detenidos desde la DGS a la cárcel sin pasar por el juzgado ${ }^{35}$. La irrupción policial sumió la actividad universitaria en un estado de permanente anormalidad: el 16 de febrero dimitieron los decanos de Económicas y Derecho de la Universidad de Madrid, y el 17 se encontraban presos unos 80 estudiantes a consecuencia de los incidentes ocurridos desde el 30 de noviembre del año anterior. El 27 de febrero fueron cerradas por tiempo indefinido las universidades de Valencia y Madrid, y en marzo la de Sevilla. La víspera, una orden del ministro Lora autorizó la Policía a instalarse de forma permanente en los recintos universitarios a las órdenes del rector y los decanos, tras de lo cual se practicaron más de dos centenares de detenciones. La cada vez más activa presencia de la fuerza pública en los recintos universitarios degeneró en enfrentamientos constantes en Madrid, Barcelona, Sevilla, Oviedo, Santiago, Málaga, Valencia y Valladolid. El 14 de marzo se produjo el desalojo del edificio principal de la Universidad de Santiago de Compostela, y ese mismo día la Policía penetró simultáneamente en cinco facultades de Madrid y protagonizó graves enfrentamientos en los que resultaron lesionados el decano de la Facultad de Económicas y varios profesores.

El día 22 de marzo, el Gobierno aprobó tres medidas con las que pretendió poner coto a la agitación estudiantil: nombró un magistrado especial con jurisdicción en todo el territorio nacional para juzgar las acciones ilegales de los estudiantes universitarios; el Gabinete conminó a las autoridades académicas a mantener con rigor la disciplina académica y se suprimió el fuero que impedía a las fuerzas policiales penetrar en los recintos universitarios sin autorización previa del rector ${ }^{36}$. Tras una nueva irrupción policial en la Complutense el 28 de marzo, el Gobierno ordenó el cierre indefinido de todos los recintos universitarios de Madrid. Desbordada por los graves incidentes de esa primavera, la Junta de Gobierno amenazó con dimitir, lo que condujo a que Lora, en desacuerdo con la presencia policial que arrebataba la capacidad de decisión a las autoridades académicas, interpelase en vano

${ }^{35}$ Informe de "Aurelio" (Francisco Romero Marín) sobre las consecuencias que han tenido las medidas del Gobierno relacionadas con la Universidad (13-II-1968), en AH.PCE, Intelectuales, movimiento estudiantil, jacket 506. Una nueva carta de Romero Marín con más datos sobre la lucha universitaria para la retirada de la Policía (27-II-1968), donde se asegura que la airada respuesta estudiantil a la medida "ha sido un fracaso de los métodos de Camilo y de los grupos ultras", en AH.PCE, Intelectuales, movimiento estudiantil, jacket 507.

${ }_{36}$ Jacques Georgel, El franquismo: historia y balance, 1939-1969 (París: Ruedo Ibérico,1971), 111-116. 
al ministro de la Gobernación. Completamente desasistido, el Lora dimitió el 5 de abril, y el 18 entró a sustituirle José Luis Villar Palasí, que retrasó la reapertura universitaria al 6 de mayo ${ }^{37}$.

A partir de mayo de 1968, el rearme autoritario del Estado franquista influyó de forma decisiva y duradera en la limitación de las oportunidades de la protesta estudiantil. El nuevo ministro de Educación, perfectamente consciente del impacto subversivo de la movilización escolar sobre la estabilidad del régimen, propuso implementar una estrategia mixta de represión y reformismo controlado. Aconsejó a Franco que "el problema universitario debe ser abordado prontamente y no cabe intentar resolverlo con medidas parciales o, aún más, considerando que todo se reduce a tumultos. De otra parte, es de subrayar que no se trata de una simple agitación juvenil que desaparezca cuando el estudiante deje de serlo o cuando por razones de edad madure su propio pensamiento, sino que, en sus raíces, responde a más profundos planteamientos que afectan a la propia estructura social contemporánea del mundo actual. La universidad en parte actúa como sismógrafo del futuro". Villar Palasí opinaba que "el problema universitario estrictamente no es sólo una cuestión de orden público, sino también un agudo problema político", y, por lo tanto, la manera de afrontarlo debidamente era mediante una acción política coordinada desde la misma Universidad - estrategia inexistente en aquellos momentos-, con el propósito de "contrarrestar la extremada politización de la misma que desde hace años se viene haciendo al margen o en contra del Régimen". La idea del ministro era despolitizar a la masa estudiantil que inundaba la Universidad pública, y, al mismo tiempo, reforzar la formación política de las minorías que debían convertirse en las futuras elites dirigentes del país, sobre todo a través del fomento de las universidades autónomas y privadas. Por último, se abordarían las reformas universitarias en sentido estricto, con un aumento de la proporción entre profesores y alumnos y un incremento de los centros docentes ${ }^{38}$. Villar Palasí también creía necesario unificar la acción gubernativa de los diferentes ministerios implicados en el problema estudiantil y universitario, limitando las actuaciones policiales directas ordenadas por el Ministerio de la Gober-

${ }^{37}$ La rebeldía estudiantil y la dimisión del ministro, en Manuel Lora Tamayo, Lo que yo he conocido. Recuerdos de un viejo catedrático que fue ministro (Cádiz: Federico Joly y Cía., 1993), 387-411. Un resumen del agitado Curso 1967-1968 en Madrid, en "Más de la mitad del curso, en 'paro forzoso"', Gaceta Universitaria (Madrid) 104 (1-VII-1968): 14-15.

${ }^{38}$ Cit. por Raúl Aguilar Cestero, "El despliegue de la Universidad Autónoma de Barcelona entre 1968 y 1973: de fundación franquista a motor del cambio democrático en Cataluña", Cuadernos del Instituto Antonio de Nebrija de Estudios sobre la Universidad no. 10 (2007): 22-24. 
nación, y creando un servicio de información eficaz que conociera de forma inmediata los planes y actividades e identificara a los miembros del movimiento estudiantil. Por lo que respecta al Ministerio de Justicia, proponía un endurecimiento de las penas, basadas en las pruebas aportadas por los servicios secretos de la Policía, ya que sin una condena de los tribunales era imposible mantener las sanciones académicas. El ministro de Información y Turismo, Villar Palasí, solicitaba a Franco un mayor control de la censura en todas las noticias que informaban de los conflictos en las universidades españolas y extranjeras, y el inicio de una campaña propagandística en favor de las reformas que iba a proponer ${ }^{39}$.

La política de reformismo controlado cedió pronto el relevo a la represión pura y simple, que se desplegó en estrategias preventivas y anticipatorias de carácter contrasubversivo: tras conocerse las inquietantes repercusiones políticas de la conmoción parisina de mayo, en junio-julio se reunieron el fiscal del Tribunal Supremo, el director general de Seguridad, el secretario general técnico del Ministerio de Educación y Ciencia (MEC), el comisario para el SEU y el secretario técnico de la Secretaría General del Movimiento (SGM) para reforzar las medidas de control de la Universidad ${ }^{40}$. Después de que, en septiembre, el subsecretario de Educación, Alberto Monreal Luque, acudiese al Alto Estado Mayor para solicitar ayuda contra la "subversión en la Universidad", el 20 de noviembre se constituyó una Comisión Delegada del Gobierno para asuntos de orden público presidida por el almirante Luis Carrero Blanco, y formada por los ministros de Gobernación, Hacienda, Educación y Ciencia y Justicia, además de por el subsecretario del Ministerio del Ejército (el titular de la cartera se encontraba enfermo) y el ministro secretario general del Movimiento, aunque en algunas ocasiones también llegó a participar en sus reuniones el capitán general de Madrid. Esta llamada "Comisión de Universidad", que se ocupó de los problemas de orden público vinculados a la conflictividad escolar, se convocó todos los miércoles en sesiones de hasta dos horas de duración, salvo un receso entre mayo de 1969 y marzo de 1970. Hacia la primavera de 1970, sus reuniones contaron con la presencia del fiscal del Tribunal Supremo Fernando Herrero Tejedor. En los años siguientes, y ante la extensión de la conflictividad, esta Comisión vería ampliado su radio de acción al conjunto de los movimientos sociales de oposición al régimen.

${ }^{39}$ Memorándum de Villar Palasí a Franco sobre la situación universitaria (6-IX-1968), en Laureano López Rodó, Memorias (2). Años decisivos (Barcelona: Plaza \& Janés-Cambio 16, 1991), 627-632 e Ysàs, Disidencias y subversión, 24.

${ }^{40}$ Ysàs, Disidencias y subversión, 23. 
Una nueva estructura contrasubversiva estatal, inspirada en los métodos de guerra psicológica contra el "enemigo interior" procedentes de Francia y los Estados Unidos, nació al calor de los sucesos de mayo de 1968. El ministro de Educación propuso la creación de una unidad de investigación para controlar los desórdenes universitarios. Se decidió limitar la intervención de la Policía en las Facultades a las alteraciones graves del orden público, y se puso en funcionamiento un servicio secreto de carácter militar para prevenir las acciones del movimiento estudiantil y fichar a sus principales integrantes. Dentro del MEC comenzó a actuar a partir del otoño de 1968 una unidad de información constituida por jefes y oficiales del Ejército, pagada con fondos de Gobernación y la SGM, y dedicada especialmente a prever las acciones del movimiento estudiantil, que quedó bajo la dirección del coronel José Ignacio San Martín. Este "Servicio Especial" amplió rápidamente su radio de acción al entorno sindical, al mundo de la cultura y al ámbito eclesiástico, dando lugar a la Organización Contrasubversiva Nacional (OCN) surgida de las reuniones semanales mantenidas en 1969 y 1970 por el vicepresidente Carrero con los ministros de Educación y Ciencia, Gobernación, Ejército, Justicia y $\mathrm{SGM}^{41}$. Protegido e impulsado por el almirante, que mantenía reuniones periódicas con San Martín desde enero de 1969, este servicio de información, dependiente en un principio del Ministerio de la Gobernación y la SGM, acabó por ser asumido directamente por el subsecretario de la Presidencia, que en marzo de 1972 lo convirtió en el Servicio Central de Documentación de la Presidencia del Gobierno (SECED). Con rango de director general, San Martín despachó desde entonces diariamente con su mentor. Así que, en cierto sentido, se podría afirmar que Villar Palasí fue el inspirador involuntario de la renovación y modernización de los servicios represivos del último franquismo ${ }^{42}$. El Gobierno ya no se planteaba depurar la Universidad, sino facilitar que las autoridades académicas lo hicieran por su cuenta, como fue el caso del rector Julio Rodríguez Martínez en la Universidad Autónoma de Madrid en 1972-1973. Con su mezcla de represión, espionaje y reforma universitaria, el ministro Villar Palasí logró acabar con los SDEU, pero no con las protestas del movimiento estudiantil, que había

${ }^{41}$ Juan María de Peñaranda y Algar, Desde el corazón del CESID (Madrid: Espasa, 2012), 19 sitúa su origen en 1968.

${ }^{42}$ Véanse Antonio M. Díaz Fernández, Los servicios de inteligencia españoles. Desde la guerra civil hasta el 11-M: historia de una transición (Madrid: Alianza, 2005), 138-179; José Ignacio San Martín, Servicio Especial. A las órdenes de Carrero Blanco (de Castellana al Aaiún) (Barcelona: Planeta, 1983) y Javier Tusell, Carrero. La eminencia gris del régimen de Franco (Madrid: Temas de Hoy, 1993), 378-380. 
entrado en una nueva fase de radicalización cuyo influjo se extendió a otros miembros de la comunidad universitaria ${ }^{43}$.

A inicios de 1969, Carrero atribuía a tres causas la subversión existente: la inmoralidad de los medios de comunicación, la actitud crítica de la Iglesia y la infiltración marxista en la Universidad ${ }^{44}$. En ese último aspecto, su sintonía de pensamiento con Franco resultaba total, ya que, en su mensaje de 1 de enero de 1969, el Jefe del Estado advirtió que "la juventud española no sería desfigurada por minúsculas agitaciones estudiantiles que fomentan en el mundo gentes sometidas a las consignas comunistas" ${ }^{\prime 4}$. Las medidas represivas se combinaron con la declaración de un estado de excepción que afectó al conjunto del territorio español y provocó la detención de cientos de militantes antifranquistas, muchos de ellos universitarios, y la huida al extranjero o la ocultación de muchos otros que temieron ser detenidos. Este nuevo dispositivo de coacción establecido por el régimen debilitó a las organizaciones antifranquistas que actuaban en la Universidad y en otros sectores de la sociedad, paralizando momentáneamente su capacidad de acción y difusión.

El asalto perpetrado por medio centenar de personas al Rectorado de la Universidad Central de Barcelona el 17 de enero de 1969, que incluyó la quema de una bandera española y el derribo de un busto de Franco, conllevó el cierre del recinto académico y la declaración del estado de excepción en todo el país a partir del día 24, tras la muerte del estudiante de $4^{\circ}$ de Derecho Enrique Ruano Casanova, miembro del Frente de Liberación Popular (FLP), que después de ser detenido junto con Dolores González Ruiz y Abilio Villena, fue asesinado de un disparo el 19 de enero por policías de la BPS, y arrojado por la ventana de un séptimo piso con el propósito de simular un suicidio $^{46}$. El estudiante madrileño Ignacio Larrazola también murió en las

\footnotetext{
${ }^{43}$ Aguilar, "El despliegue de la Universidad Autónoma de Barcelona”, 142.

${ }^{44}$ Tusell, Carrero, 379.

${ }^{45}$ Ezequiel Ander-Egg, La rebelión juvenil (Madrid: Marsiega, 1980), 33.

${ }^{46}$ Los sucesos de Barcelona, en "El día que asaltaron el rectorado de Barcelona", Gaceta Universitaria 134-135 (2 $2^{\text {a }}$ quincena enero 1970): 5. La muerte de Ruano, en Ana Domínguez Rama, "Cinco días de manipulación informativa: la noticia de la muerte de Enrique Ruano en la prensa franquista”, en Manuel Bueno, José Hinojosa y Carmen García (coords.), Actas del I Congreso sobre la Historia del PCE, 1920-1977. Oviedo, 6, 7 y 8 de mayo de 2004 (Madrid: Fundación de Investigaciones Marxistas, 2007, CD-ROM; Julio Antonio García Alcalá, Historia del "Felipe" (FLP, FOC y ESBA): de Julio Cerón a la Liga Comunista Revolucionaria (Madrid: CEPC, 2001), 245-250; Benito Sanz Díaz, La oposició universitària al franquisme, València, 1939-1975 (Valencia: Servei d'Informació a l'Estudiant-DISE, Universidad de Valencia, ¿1999?), 87 y “La radicalización del movimiento universitario valenciano, 1968-1975. La proliferación de partidos políticos", en Benito Sanz Díaz y Ramón Ignacio Rodríguez Bello (eds.), Memoria del anti-
} 
manifestaciones de protesta convocadas tras el asesinato. La Policía tomó a viva fuerza las facultades de Madrid; se prohibieron reuniones, cámaras, asambleas, actividades culturales y la colocación de carteles informativos, mientras que los miembros más conspicuos del SDEU de Madrid fueron sistemáticamente detenidos ${ }^{47}$. La suspensión de derechos se mantuvo hasta el 21 de marzo. Durante las dos primeras semanas de vigencia del estado de excepción se detuvo a más de trescientas personas, en su mayoría escolares, y a su conclusión se había encarcelado a 735 personas, 315 de ellas estudiantes $^{48}$. Por esas fechas, Antonio González Pacheco (a) Billy el Niño, policía de la BPS que había actuado contra el sindicato clandestino Comisiones Obreras (CCOO), se afincó en la Facultad de Filosofía y Letras, y fue denunciado ante los tribunales por los malos tratos que dispensaba a los alumnos ${ }^{49}$.

La represión franquista ya no fue sólo académica (con el corolario habitual de expedientes, inhabilitaciones, cierre de las universidades y dispersión de los centros) o informativa (con el restablecimiento de la censura de prensa en febrero-abril), sino también policial y gubernativa, basada en registros nocturnos y detenciones, destierros, malos tratos en comisaría, multas a instancia de la BPS, negativa a la expedición de certificados de buena conducta, pasaportes y carnets de conducir, prohibición arbitraria de realizar Milicias Universitarias y juicios ante el TOP y los tribunales militares en aplicación del Decreto de 21 de septiembre de 1960 sobre Bandidaje y Terrorismo, que consideraba rebelión militar la divulgación de noticias falsas o tendenciosas, las reuniones de la oposición o las huelgas políticas. La represión disuasoria se puso a la orden del día. Como dijo Fraga en la lectura del comunicado oficial que anunciaba el estado de excepción, "efectivamente es mejor prevenir que curar, no vamos a esperar una jornada de mayo para que luego sea más difícil y más caro el arreglo" ${ }^{50}$.

franquismo. La Universidad de Valencia bajo el franquismo, 1939-1975 (Valencia: Universidad de Valencia, 1999), 282-285 y Valdevira, La oposición estudiantil al franquismo, 143-149.

${ }^{47}$ Davira Formentor (seud. de Pablo Lizcano y Mamen Gutiérrez), “Universidad: crónica de siete años de lucha”, en Horizonte Español 1972 (París: Ruedo Ibérico, 1972), II, 206.

${ }^{48}$ Aguilar, "El despliegue de la Universidad Autónoma de Barcelona", 151. Sobre el estado de excepción declarado el 24-I-1969 y su justificación oficial, véase Ysàs, Disidencias y subversión, 29-34.

${ }^{49}$ Vanguardia. Portavoz de la Organización Universitaria de Madrid del PC, 26-IV-1970: 9-10). Véase también la denuncia de la Organización Universitaria de Madrid del PCE, "Declaración de la Organización Universitaria sobre la presencia de la policía" (X-1970), documentación cortesía de Elena Sánchez Durán.

${ }^{50}$ Cit. por Álvarez Cobelas, Envenenados de cuerpo y alma, 276. La represión de 19681970, en SDEU de Madrid, “La Junta de Estudiantes denuncia la represión” (Madrid, V-1969), 
Para aquel entonces, la OCN y luego el SECED trataron de contrarrestar y anular por todos los medios las actividades contrarias al régimen. Contando con un presupuesto de gastos que aumentó de 15 millones de pesetas en 1970 a 70 millones en $1973^{51}$, la estructura contrasubversiva del Gobierno recurrió a colaboradores infiltrados en las aulas (380 a fines de mayo de 1970), cuyo reclutamiento se efectuaba de forma preferente en los cursos básicos de oficiales, sobre todo de la Guardia Civil. Para la acción psicológica positiva se echó mano de las moribundas APEs. También se buscó apoyo entre los elementos juveniles de la extrema derecha para luchar contra la subversión universitaria, y se llegó a formar monitores para dirigir estos grupos hacia la acción violenta. Así sucedió con la Defensa Universitaria, que, en el momento de su irrupción en el campus de la Ciudad Universitaria, hacia mediados de marzo de 1968, contaba con un centenar de integrantes (entre ellos el príncipe Alfonso de Borbón y Dampierre) radicados en la Facultad de Derecho. Al año siguiente, la formación "ultra" mudó de dirección y de firma, pasando a depender de los servicios de información de la Guardia Civil bajo la denominación de Guerrilleros de Cristo Rey, cuya colusión con las instancias oficiales del régimen fue constantemente denunciada por la prensa estudiantil clandestina ${ }^{52}$. Bajo la tutela del coronel de caballería Federico Quintero Morente (entonces miembro del SECED muy próximo a la CIA, y luego jefe superior de Policía de Madrid en 1976), los GCR reclutaron a sus afiliados entre los grupúsculos fascistas ya existentes: Hermandad Nacional Universitaria, Hermandad Sacerdotal Española, los neonazis de Joven Europa y los sectores más radicalizados del SEU. Otras formaciones ultrade-

en AH.PCE, Fuerzas de la Cultura, caja 125 (con modos de represión y una relación de represiones individuales y colectivas). Véase también Antonio Nadal Sánchez, "El movimiento universitario y la represión”, en Carreras Ares y Ruiz Carnicer (eds.), La universidad española bajo el régimen de Franco, 455-467. La generalización de la dinámica de acción-represión impuso a elaborar un protocolo de comportamiento durante las movilizaciones y la eventual detención. Sobre el modo de afrontar la represión, véase "Normas prácticas de seguridad para todos los estudiantes antifascistas" (s.f.), en AH.PCE, Fuerzas de la Cultura, caja 125, cit. por Matilde Eiroa y Encarnación Barranquero, "Notas sobre la lucha y la defensa: 'Normas de seguridad para todos los estudiantes antifascistas', en Juan José Carreras Ares y Miguel Ángel Ruiz Carnicer (eds.), La universidad española bajo el régimen de Franco. Actas del Congreso celebrado en Zaragoza entre el 8 y el 11 de noviembre de 1989 (Zaragoza: Institución Fernando El Católico, 1991), 587-599, y Hernández Sandoica, Ruiz Carnicer y Baldó Lacomba, Estudiantes contra Franco, 427-430.

${ }^{51}$ San Martín, Servicio Especial, 24.

52 "Documentos del Movimiento Estudiantil" (6-III-1970), en AH.PCE, Publicaciones de la Universidad, vol. 20/5. Algunos testigos recuerdan que los GCR iban por los campus ataviados con brazaletes bicolores y ayudando a los antidisturbios. 
rechistas, como Acción Universitaria Nacional (AUN, creada hacia 1969 por el coronel San Martín), la Asociación Nacional de Universitarios Españoles (ANUE), la Hermandad de Santa Cecilia, los Comandos de Lucha Antimarxista, el Movimiento Social Español (MSE) o el Partido Español Nacional Socialista (PENS) -todas ellas controladas en diverso grado por los servicios de información y vigilancia del Gobierno-, tuvieron menor incidencia en el conflicto universitario ${ }^{53}$.

La decadencia del movimiento estudiantil antifranquista, que culminaría su descomposición en junio de 1976, se inició en el Curso 1972-1973, en vista de la dura represión gubernativa y académica y de los efectos de la política selectiva prevista en la Ley General de Educación. A inicios de los setenta, Carrero seguía tratando de imponer la "máxima disciplina" en la Universidad. El entonces director general de Universidades, Luis Suárez Fernán$\mathrm{dez}$, fue recibido en el palacete de la Castellana en una veintena de ocasiones para tratar cuestiones relativas a la enseñanza superior con el almirante, que veía ominosos paralelismos entre la contestación universitaria de entonces y la revuelta escolar que había protagonizado la FUE de 1929 a $1931^{54}$. Esta inquietud era compartida y amplificada por los sectores más irreductibles del régimen: hacia octubre de 1972, el capitán general de Cataluña, Alfonso Pérez-Viñeta Lucio, notorio por su tendencia "azul", propuso la refundación del sindicalismo estudiantil falangista, ya que, "hoy más que nunca nuestra Universidad está necesitada de la resurrección del SEU para desterrar la subversión en el más alto centro docente de España". La propuesta, difundida profusamente por los medios oficiales, en especial el vespertino Pueblo, contó con el apoyo de gran parte de la extrema derecha como la AUN, pero el FES, que seguía oponiéndose a la "prostitución" y burocratización del SEU, anunció que "cualquier intento de montar o refundar aparatos de control estatal, máxime si se utiliza o se ampara tras terminología o símbolos falangistas, será atacada con la dureza que ya se ha aplicado en otras ocasiones" ${ }^{\prime 5}$.

Las enquistadas opiniones de Carrero sobre la juventud estudiantil y el problema de la educación pública se hicieron cada vez más beligerantes y alejadas de la realidad social. Poco antes de su muerte afirmaba que "se trata

${ }^{53}$ Sobre estos grupos, véase Mariano Sánchez Soler, Los hijos del 20-N: historia violenta del fascismo español (Madrid: Temas de Hoy, 1993).

${ }^{54}$ Tusell, Carrero, 377.

${ }^{55}$ Frente de Estudiantes Sindicalistas, "Sobre la refundación del SEU” (ca. X-1972), documentación cortesía de Elena Sánchez Durán, Francisco A. Blanco y J. Lorenzo García, "Hacia una Historia del FES (VII)", El Rastro de la Historia, 8. Disponible en http://www.rumbos.net/ rastroria/rastroria08/HistoriaFES_VII.htm [Consultado 10/02/2020]. 
de formar hombres, no maricas, y esos melenudos trepidantes que alguna vez se ven no sirven ni con mucho a este fin [...] Hay que borrar de los cuadros del profesorado de la Enseñanza General Básica y de la Universidad a todos los enemigos del Régimen y hay que separar de la Universidad a todos los alumnos que son instrumento de subversión". Pretendía a esas alturas que una juventud bien formada en las doctrinas del Movimiento y adiestrada por el Ejército en cursos de educación premilitar - un retorno a las estrategias de movilización fascista de los años cuarenta- expulsaría de las instituciones educativas a los profesores y alumnos contrarios al régimen ${ }^{56}$.

\section{Epílogo: aperturismo controlado y tolerancia institucional (1974-1976)}

Tras el asesinato del almirante a fines de 1973, los gobiernos presididos por Arias Navarro coincidieron con el momento del abandono de la estrategia de ruptura por parte de la oposición, consumada con la creación de la Coordinadora Democrática en marzo de 1976. La disminución de la represión, plasmada en la retirada de la Policía de los campus, favoreció un efímero relanzamiento de la movilización universitaria en 1974-1975, en coincidencia con la promulgación del Decreto 2.925/74 de 17 de octubre (BOE no 253 del 22) sobre Participación Estudiantil elaborado por el ministro Cruz Martínez Esteruelas. Esta normativa y la Orden Ministerial de 21 de octubre, que regularon provisionalmente la participación estudiantil en la Universidad, respondían al aperturismo controlado preconizado por el Gobierno según el "espíritu del 12 de febrero". En el primer gobierno de la Monarquía, el ministro Carlos Robles Piquer trató de facilitar y canalizar la participación mediante una reforma en profundidad del Decreto de 17 de octubre de 1974, que permitió ampliar el alcance de las libertades de reunión y expresión, al tiempo que se daban pasos parciales en la dirección de una mayor autonomía universitaria. Se limpiaron las pintadas de las paredes, se habilitaron lugares para la fijación de carteles y la Policía fue retirada definitivamente de los recintos universitarios y sus alrededores. Pero los intentos de aplicar los postulados más liberalizadores del Decreto estimularon las movilizaciones de protesta, cuyo auge se manifestó en el incremento de la circulación de la prensa ilegal de partido, la proliferación de la propaganda clandestina, las jornadas de lucha por la amnistía, las asambleas, los actos culturales, las manifestaciones, los encierros, los desalojos, las manifestaciones y los cie-

\footnotetext{
${ }^{56}$ Cit. por Tusell, Carrero, 430.
} 
rres más o menos forzados de los recintos universitarios ${ }^{57}$. La última gran batalla librada por el movimiento estudiantil antifranquista tuvo lugar entre diciembre de 1975 y marzo de 1976, con la mira puesta en el derrocamiento del régimen mediante la ruptura democrática que preconizaba la Junta Democrática animada por el Partido Comunista de España (PCE). Pero, para ese entonces, la protesta escolar ya estaba en pleno retroceso, anticipando su definitiva sustitución por la política de partidos.

Las políticas de control de las aulas implementadas por el régimen franquista en sus diferentes etapas trataron de acompasarse con la evolución sociológica y política del movimiento estudiantil: el "atroz desmoche" que padeció la Universidad española en la inmediata posguerra vino acompañado de la implantación de un modelo escolar de raíz totalitaria, que implicaba el encuadramiento obligatorio del estudiantado bajo principios semicastrenses, y la consideración del SEU como cantera privilegiada de los futuros cuadros políticos del régimen. Esa estrategia de control paternalista y coactivo empezó a entrar en crisis a mediados de los cincuenta, cuando el acceso a las aulas de la nueva generación de estudiantes que no había protagonizado la Guerra Civil trajo consigo reclamaciones de autonomía universitaria que marcaron el ocaso del modelo de sindicato único y obligatorio. Desbordado por la insumisión escolar, el régimen optó por incrementar la represión, al tiempo que trataba de modular la protesta con el fomento de asociaciones "profesionales" y "apolíticas" de carácter oficioso. Esta estrategia del palo y la zanahoria se saldó con un rotundo fracaso, y abrió las compuertas al gran ciclo de movilización escolar desarrollado entre 1965 y 1973, que trató de ser contrarrestado desde el Gobierno con la puesta en práctica de la estrategia paranoide de "lucha contra la subversión".

Desde los sucesos de 1956, el Estado franquista siempre fue a remolque de la protesta universitaria, alternando de forma errática estrategias facilitadoras o represivas que no hicieron sino acentuar el diapasón de la disidencia escolar, que en los años sesenta acabó por convertirse en el movimiento de oposición por antonomasia del régimen dictatorial. Cuando, tras el asesinato de Carrero, los gobiernos tardofranquistas presididos por Arias ensayaron una tímida apertura institucional, ya era demasiado tarde. Se cumplía una vez más el viejo adagio de que los reformistas de última hora son los enterradores de los regímenes políticos alérgicos al cambio.

${ }^{57}$ Sobre las huelgas del inicio del segundo trimestre del curso 1974-1975, véase Equipo Límite: La agonía de la Universidad franquista (Barcelona: Laia, 1976), 68-123. 
Fuentes

AFPI, AJMAH Archivo de la Fundación Pablo Iglesias, Archivos de José Manuel Arija Hernández (Alcalá de Henares).

AH.PCE Archivo Histórico del Partido Comunista de España (Madrid).

AJRG Archivo Joaquín Ruiz-Giménez (UC3M, Getafe).

BOE Boletín Oficial del Estado.

FUE, APSR Fundación Universitaria Española, Archivo Pedro Sáinz Rodríguez (Madrid).

Bibliografía

ÁGuILA ToRRES, JUAN JosÉ DEL. El TOP. La represión de la libertad (1963-1977). Barcelona: Planeta, 2001.

Aguilar Cestero, Raúl. "El despliegue de la Universidad Autónoma de Barcelona entre 1968 y 1973: de fundación franquista a motor del cambio democrático en Cataluña". Cuadernos del Instituto Antonio de Nebrija de Estudios sobre la Universidad, 10 (2007): 13-199.

ÁLVAREZ CoBElas, JosÉ. Envenenados de cuerpo y alma. La oposición universitaria al franquismo en Madrid (1939-1970). Madrid: Siglo XXI, 2004.

ANDER-EGG, EzEQUIEL. La rebelión juvenil. Madrid: Marsiega, 1980.

Blanco Moral, Francisco. "El Frente de Estudiantes Sindicalistas: Una manifestación de la oposición falangista al régimen de Franco". Espacio, Tiempo y Forma, Serie V: historia Contemporánea, III, 2 (1990): 191-209.

Claret Miranda, Jaume. El atroz desmoche. La destrucción de la Universidad española por el franquismo, 1936-1945. Barcelona: Crítica, 2006.

COLOMER I CALSINA, Josep MARIA. Els estudiants de Barcelona sota el franquisme. Barcelona: Curial, 1978, 2 vols.

Crexell i PlayÀ, JoAn. La caputxinada. Barcelona: Edicions 62, 1984.

DAVEnPort, Christian. "The Weight of the Past: Exploring Lagged Determinants of Political Repression". Political Research Quarterly, 49, 2 (junio 1996): 377-403.

DAVIRA FORMENTOR (seud. de Pablo Lizcano y Mamen Gutiérrez). "Universidad: crónica de siete años de lucha”. En Horizonte Español 1972. París: Ruedo Ibérico, 1972, II, 179-235.

Della Porta, Donatella. Social Movements, Political Violence, and the State. A Comparative Analysis of Italy and Germany. Cambridge: Cambridge University Press, 1995. 
DíAz Fernández, Antonio M. Los servicios de inteligencia españoles. Desde la guerra civil hasta el 11-M: historia de una transición. Madrid: Alianza, 2005.

Dionisio Vivas, Miguel Ángel. "La prohibición de la carta pastoral 'Lecciones de la guerra y deberes de la paz' y los conflictos entre la Iglesia y el Gobierno español en el otoño de 1939”. Toletana, 20 (2008), 75-102.

Domínguez Rama, AnA. "Cinco días de manipulación informativa: la noticia de la muerte de Enrique Ruano en la prensa franquista". En Manuel Bueno, José Hinojosa y Carmen García (coords.), Actas del I Congreso sobre la Historia del PCE, 1920-1977. Oviedo, 6, 7 y 8 de mayo de 2004. Madrid: Fundación de Investigaciones Marxistas, 2007, CD-ROM.

EIROA, Matilde y ENCARNACión BARRANQUERo. "Notas sobre la lucha y la defensa: 'Normas de seguridad para todos los estudiantes antifascistas'”. En Juan José Carreras Ares y Miguel Ángel Ruiz Carnicer (eds.), La universidad española bajo el régimen de Franco. Actas del Congreso celebrado en Zaragoza entre el 8 y el 11 de noviembre de 1989. Zaragoza: Institución Fernando El Católico, 1991: 587-599.

EquiPo LímITE (Georgina Cisquella, José Luis Erviti, Maite Goicoechea, José Luis Gómez Mompart y José A. Sorolla). La agonía de la Universidad franquista. Barcelona: Laia, 1976.

- [La] Falange ante la Universidad. Discursos y conferencias del V Consejo Nacional del SEU (Alcalá de Henares, 1941). Madrid: SEU-Taller Gráfico Marsiega, 1942.

FARGa, MANUEL JUAN. Universidad y democracia en España (30 años de lucha estudiantil). México: Era, 1969.

Fernández Soria, JuAn Manuel y Alejandro Mayordomo PÉrez. "En torno a la idea de Universidad en la España de la post-guerra (1939-1943)". En $7^{\text {th }}$ International Standing Conference for the History of Education. Educación superior y sociedad. Perspectivas históricas. Salamanca: Depto. de Historia de la Educación, 1985, II, 249-262.

García Alcalá, Julio Antonio. Historia del "Felipe" (FLP, FOC y ESBA): de Julio Cerón a la Liga Comunista Revolucionaria. Madrid: CEPC, 2001.

Garelli, Franco. "Controllo sociale". En Norberto Bobbio, Nicola Matteucci y Gianfranco Pasquino (eds.), Dizionario di Politica. Turín: TEA/UTET, 1990, 232-234.

GEORGEL, JACQUES. El franquismo: historia y balance, 1939-1969. París: Ruedo Ibérico,1971.

Gil Robles y Quiñones, José María. La Monarquía por la que yo luché. Páginas de un diario (1941-1954). Madrid: Taurus, 1976. 
GINER, SALVADOR. “Universitat, moviment estudiantil i poder polític a l'Estat espanyol, 1939-1975". Aïnes, 2 (diciembre 1975), 65-101.

GuitarTe JosÉ Miguel. Discursos y escritos en una etapa del SEU. Madrid: Eds. Haz, 1941.

HERMET, GUY. Los católicos en la España franquista, II: Crónica de una dictadura. Madrid: CIS-Siglo XXI, 1986.

Hernández Sandoica, Elena, Miguel Ángel Ruiz Carnicer y Marc Baldó LACOMBA. Estudiantes contra Franco (1939-1975). Oposición política y movilización juvenil. Madrid: La Esfera de los Libros, 2007.

Jato Miranda, David. La rebelión de los estudiantes. Apuntes para una historia del alegre SEU. Madrid: el autor, 1975.

Jáuregui, Fernando y Pedro Vega. Crónica del antifranquismo. Barcelona: Argos Vergara, 1983-1984, 2 vols.

LAÍN ENTRALGO, PEDRo. Descargo de conciencia (1930-1960). Barcelona: Instituto de Estudios Turolenses/Galaxia Gutenberg/Círculo de Lectores, 2003.

López Rodó, LaUREano. Memorias (1). Barcelona: Plaza \& Janés-Cambio 16, 1990.

López Rodó, Laureano. Memorias (2). Años decisivos. Barcelona: Plaza \& Janés-Cambio 16, 1991.

Lora Tamayo, Manuel. Lo que yo he conocido. Recuerdos de un viejo catedrático que fue ministro. Cádiz: Federico Joly y Cía., 1993.

MANUEL DE SANTA CRUZ (seud. de Alberto Ruiz de Galarreta). Apuntes y documentos para la historia del tradicionalismo español, volumen 1. Madrid: La Editorial Católica, 1979.

MohedAno, José MARÍA. "Una década de lucha en la Universidad”. En Historia del franquismo. Franco, su régimen y la oposición. Madrid: Diario 16, 1985, II, 690-691.

Montero García, Feliciano. “De la JUMAC a la JEC. Aproximación a la historia de la AC estudiantil". En Feliciano Montero (coord.), Juventud Estudiante Católica (1947-1997). Madrid: JEC, 1998, 21-71.

Montoro Romero, Ricardo. La Universidad en la España de Franco (19391970). Un análisis sociológico. Madrid: CIS, 1981.

NADAL SÁnCHEZ, ANTONio. "El movimiento universitario y la represión". En Juan José Carreras Ares y Miguel Ángel Ruiz Carnicer (eds.), La universidad española bajo el régimen de Franco. Actas del Congreso celebrado en Zaragoza entre el 8 y el 11 de noviembre de 1989. Zaragoza: Institución Fernando El Católico, 1991), 455-467.

Peñaranda y Algar, Juan María De. Desde el corazón del CESID. Madrid: Espasa, 2012. 
Rodríguez LóPEz, CARolina. La Universidad de Madrid en el primer franquismo: ruptura y continuidad [1939-1951]. Madrid: Ed. Dykinson-Universidad Carlos III de Madrid, 2002.

Rubio Mayoral, Juan Luis. Disciplina y rebeldía: los estudiantes en la Universidad de Sevilla (1939-1970). Sevilla: Secretariado de Publicaciones, Universidad de Sevilla, 2005.

Ruiz CARnicer, Miguel Ángel. El Sindicato Español Universitario (SEU) 1939-1965: La socialización política de la juventud universitaria en el franquismo. Madrid: Siglo XXI, 1996.

San Martín, José Ignacio. Servicio Especial. A las órdenes de Carrero Blanco (de Castellana al Aaiún). Barcelona: Planeta, 1983.

Sánchez Durán, Elena, Francisco A. Blanco y J. Lorenzo García. "Hacia una Historia del FES (VII)". El Rastro de la Historia, 8. Disponible en http://www.rumbos.net/rastroria/rastroria08

SÁnCHez Soler, MaRiano. Los hijos del 20-N: historia violenta del fascismo español. Madrid: Temas de Hoy, 1993.

SANZ DíAZ, BENITO. "La radicalización del movimiento universitario valenciano, 1968-1975. La proliferación de partidos políticos". En Benito Sanz Díaz y Ramón Ignacio Rodríguez Bello (eds.), Memoria del antifranquismo. La Universidad de Valencia bajo el franquismo, 1939-1975. Valencia: Universidad de Valencia, 1999, 276-345.

SANZ DíAz, BENITo. La oposició universitària al franquisme, València, 19391975. Valencia: Servei d'Informació a l'Estudiant-DISE, Universidad de Valencia, ¿1999?

Stohl, Michel y George A. Lopez. The State as Terrorist. Westport: Greenwood, 1984.

Tilly, Charles. From Mobilization to Revolution. Nueva York: Random House/McGraw-Hill, 1978.

Tilly, ChARLES. Regimes and Repertories (Chicago-Londres: The University of Chicago Press, 2006.

TuSELl GómEZ, JAVIER. Carrero. La eminencia gris del régimen de Franco. Madrid: Temas de Hoy, 1993.

VALDEVIRA GONZÁLEZ, GREGORIO. La oposición estudiantil al franquismo. Madrid: Síntesis, 2006.

VILAR, SERGIo. Historia del antifranquismo, 1939-1975. Espulgues de Llobregat: Plaza \& Janés, 1984.

YSÀs, PERE. Disidencias y subversión. La lucha del régimen franquista por su supervivencia, 1960-1975. Barcelona: Crítica, 2004. 